\title{
The Library and Information Service
}

\section{New bibliographies from the Library \\ Reading List for Trainees: Basic Sciences OP21}

The Library has prepared a revised edition of this reading list which aims to assist trainees in their preparation for the examinations. Our thanks to the many subject specialists for their expert advice. Copies are available from the Publications Department, price £2.00.

\section{Maudsley Lectures and Lecturers}

In 1920 Sir James Crichton-Browne gave the first Maudsley Lecture when he spoke about the current state of psychiatry. Since then, with a few exceptions, such as the years of World War II, there has been a Maudsley Lecture each year. The majority of these have appeared in the Journal of Mental Science or the British Journal of Psychiatry. They offer the views of leading psychiatrists on a wide range of psychiatric topics.
The Library has compiled a bibliography of these lectures and anyone wishing to obtain a copy should contact the Library.

Psychiatric Instruments and Rating Scales: a select bibliography

Encouraged by the good feedback received on this publication, produced in 1992, we are working on a revised and enlarged edition which will include over 600 citations to original and early papers describing psychiatric instruments. Please contact the Library for further details and an order form.

\section{List of Books Suitable for a Psychiatric}

Library 1988-1993

The Library has been producing these lists annually for some years. We have decided to review these reading suggestions and are producing a consolidated list of current works which we hope will assist hospital librarians and clinical tutors with their book selection. Further details are available from the Librarian.

SUSAN FLOATE, Librarian, The Royal College of Psychiatrists

\section{Director for the Research Unit}

The Royal College of Psychiatrists will be advertising for a Director of the Research Unit to commence in the Autumn 1994. The Director will be responsible for continuing the current research programme and developing in agreement with the President and Registrar the future research policy and programme of the Unit. The appointment may be full-time or part-time, with a maximum term of five years. The Director may be employed directly by the College or seconded from an academic or clinical setting. The College will be advertising for the post in the British Medical Journal on 5 March 1994.

For further details please contact The Secretary, Royal College of Psychiatrists, 17 Belgrave Square, London SW 1X 8PG.

\section{Defeat Depression Action Week}

\section{3-11 March 1994}

Aims

* to raise awareness about depression

* to reduce the stigma associated with it

* to give advice on seeking help

There will be a two mile fun run in Hyde Park, London, as part of the Defeat Depression
Action Week. This will start at 11 a.m. on Sunday, 6 March. The entry fee is $£ 3$ and the total amount received in entry fees will be matched by a commercial company and all proceeds will be donated to the Defeat Depression Campaign.

If you are interested in this event please contact Christine Gear on 0712352351. 